\title{
STRESS DISTRIBUTION IN THE NASOMAXILLARY COMPLEX FOLLOWING APPLICATION OF ORTHOPAEDIC HEADGEAR FORCES- A 3-DIMENSIONAL FEM STUDY
}

\author{
Suruchi Seth', Shivalinga B. $M^{2}$, Sunil Seth ${ }^{3}$, Gurinderjit Singh Nagi ${ }^{4}$ \\ ${ }^{1}$ Associate Professor, Department of Dentistry, PIMS, Jalandhar. \\ ${ }^{2}$ Former Professor and HOD, Department of Orthodontics, JSS Dental College and Hospital, Mysore. \\ ${ }^{3}$ Assistant Professor, Department of Radiodiagnosis, PIMS, Jalandhar. \\ ${ }_{4}^{4}$ Associate Professor, Department of Surgery, PIMS, Jalandhar.
}

\section{BACKGROUND}

\section{ABSTRACT}

Extraoral force has been in use in orthodontics since Cellier introduced it in early 1800s. Like many other treatment modalities, interest in headgears and the understanding of its probable effect has varied over the years. From only dental changes to skeletal changes affecting the cranial base structures as well, all have been attributed to headgear use at various times. At present, it is well established that headgears have a retarding effect on the growth and development of maxilla. However, the exact biomechanical effect of different force directions on the sutural response is still under consideration.

\section{MATERIALS AND METHODS}

The present study was undertaken to examine the effect of posteriorly directed headgear forces on the various nasomaxillary sutures. FEM model was created having 236685 elements and 56052 nodes and 1 Kgf force was applied at $-30^{\circ}, 0^{\circ}, 30^{\circ}, 52.4^{\circ}$ and $60^{0}$ to the functional occlusal plane.

\section{RESULTS}

1. In loading with forces in $52.4^{\circ}$ and $60^{\circ}$ superior directions, compressive stresses were similarly generated in most anatomic areas and both the normal and shear stresses reduced and exhibited a convergence to a certain level.

2. As the force direction approached that of the CRe, mean principal stresses approached a uniform level of compressive stress.

3. Maximum strain or displacement of all the sutures was observed at a force direction of $-30^{\circ}$. Strain approached to a minimum level at a force direction of $30^{\circ}$ and $52.4^{0}$.

\section{CONCLUSION}

These findings show that the stress distribution in the sutures varies in relation to the direction of force. Force applied in the direction closest to that of the CRe may produce the most effective sutural modification for controlling maxillary growth. This is an observational study.

\section{KEYWORDS}

FEM, Nasomaxillary Complex, Sutures, CRe, Stress.

HOW TO CITE THIS ARTICLE: Seth S, Shivalinga BM, Seth S, et al. Stress distribution in the nasomaxillary complex following application of orthopaedic headgear forces- a 3-dimensional fem study. J. Evolution Med. Dent. Sci. 2017;6(91):6510-6514, DOI: $10.14260 /$ jemds/2017/1413

\section{BACKGROUND}

The use of extraoral force began in the early 1800s when Cellier developed cervical and occipital traction to prevent luxation of mandible. ${ }^{1}$ However, the widespread acceptance of orthopaedic therapy was brought about by Silas Kloehn's interesting study in 1947, where he showed headgear therapy to be an effective treatment for patients with maxillary excess. $^{2}$

Since then, various types of headgears have been developed for clinical use in orthodontics. ${ }^{3}$ The response of the craniofacial structures to extraoral appliances continues to be a major concern for orthodontists. An understanding of orthopaedic effects of extraoral force depends on achieving

'Financial or Other Competing Interest': None.

Submission 16-09-2017, Peer Review 11-11-2017,

Acceptance 17-11-2017, Published 27-11-2017.

Corresponding Author:

Dr. Suruchi Seth,

Department of Dentistry,

Punjab Institute of Medical Sciences,

Jalandhar.

E-mail: suruchikalra@yahoo.com

DOI: $10.14260 /$ jemds $/ 2017 / 1413$

\section{(c) (i) $(9$}

an understanding of the biological response of the maxillofacial sutures to clearly defined force systems. ${ }^{4}$ Animal studies have shown that headgear use results in compression or stretching of maxillary sutures resulting in remodelling changes of large magnitude and the force applied was also transmitted to adjacent bones with increased sutural activity. ${ }^{5}$

However, the interpretation of results in treatment proves extremely complicated. Variations in growth pattern of the craniofacial complex, timing of maturation, variation in tooth movement and variation in magnitude, direction, point of attachment of applied forces form a myriad of inter-related factors which greatly hinder precise analysis of treatment effects.

Due to these drawbacks, various animal studies $4,6,7,8,9,10$ and cephalometric studies $1,11,12,13,14,15,16,17,18,19,20,21,22$ were carried out. Though these studies gave a lot of useful information, they could not quantify the stress and strain across the sutures. This led to the use of models to access the levels of stress and strain across the sutures. Strain gauges ${ }^{5}$, holography,23,24,25,26 laser metrology 11 and laser speckle interferometry ${ }^{27}$ are all highly sensitive techniques, able to measure extremely small initial deformations of bone on macerated skull. Unfortunately, most of these techniques are 
limited in their ability to measure internal displacements and stress-strain levels in a complicated structure such as the craniofacial skeleton. ${ }^{28}$

To overcome the drawbacks of the aforementioned methods, FEA study was taken up to study the stress distribution in various sutures of the nasomaxillary complex on application of various headgear forces.

\section{Aims and Objectives}

The objectives of the Present Study are

- To study the stress distribution in the various nasomaxillary sutures during application of headgear forces.

- To study the displacement of various nasomaxillary sutures during application of headgear forces.

- To compare stress distribution and displacement of nasomaxillary sutures on application of headgear forces in various directions.

\section{MATERIALS AND METHODS}

A three-dimensional mathematical finite element model was generated for analysis from spiral CT scan images of $3 \mathrm{~mm}$ sections of an intact skull, with full complement of teeth. The sections obtained in DICOM format and the data were fed into the computer. Using the MIMICS software, these cross sections were converted into a three-dimensional mathematical model. Thus, a virtual geometric model of the skull was obtained. The virtual geometric model is divided into several finite elements. The mesh chosen for the study was HyperMesh 7.0, using a four-noded tetrahedral element. ANSYS software was used to create the finite element model. The finite element model thus built comprised of 236685 elements and 56052 nodes. All the nasomaxillary sutures like Frontomaxillary, Sphenomaxillary, Frontozygomatic, Sphenozygomatic, Temporozygomatic and Lamina Cribrosa were generated in the finite element model.

Mechanical properties such as Young's modulus and Poisson's ratio of bone, tooth and sutures were fed to the finite element model.28,29,30,31 All materials were assumed to be isotropic and to follow elastic behaviour. Because no direct data were available for the material properties of sutures, two values of stiffness were introduced. Firstly, the modulus of elasticity of suture was considered as half of the stiffness of cortical bone and secondly, stiffness was reduced to a minimum of $\mathrm{E}=1 \mathrm{~N} / \mathrm{mm}^{2}{ }^{28}$ Due to the initial character of force application and because no changes in time under force load of the apparent Young's modulus occurred, it was not necessary to take viscoelasticity into consideration.

\begin{tabular}{|c|c|c|}
\hline Material & Modulus of Elasticity & Poisson's Ratio \\
\hline Bone & $12,200 \mathrm{MPa}$ & 0.3 \\
\hline Tooth & $20,000 \mathrm{MPa}$ & 0.3 \\
\hline Sutures & $6,850 \mathrm{MPa}$ & 0.3 \\
\hline \multicolumn{3}{|c|}{ Table 1. Mechanical Properties of Various Materials } \\
\hline
\end{tabular}

The study is observational in nature.

The model was constrained at the Foramen Magnum to prevent sliding movement of the model, simulating clinical application of orthopaedic extraoral forces to patients. The generated model was then strained to a load of $1.0 \mathrm{Kgf}$ applied at the first molar region in the 5 prescribed directions: $-30^{\circ}$, parallel, $30^{\circ}$ superior, $52.4^{\circ}$ superior and $60^{\circ}$ superior to the occlusal plane to simulate the various clinical situations. A $52.4^{0}$ superior direction was demonstrated in advance to connect the centre of resistance of the nasomaxillary complex and the first molar. ${ }^{32}$ The load was applied and the mean principal stress, shear stress and strain were studied using the ANSYS solver.

Following Statistical Methods were applied in the Present Study-

1. One-Way ANOVA

2. Scheffe's Post Hoc test

All the statistical operations were done through SPSS for Windows (Version 15 evaluation Version, 2006), SPSS Inc. New York

\section{RESULTS}

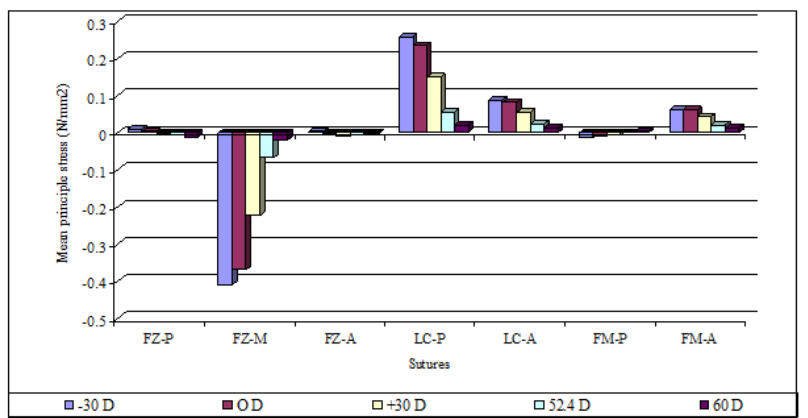

Graph 1. Mean Principal Stresses in the Anatomic Areas Resisting Upward Displacement of the Complex

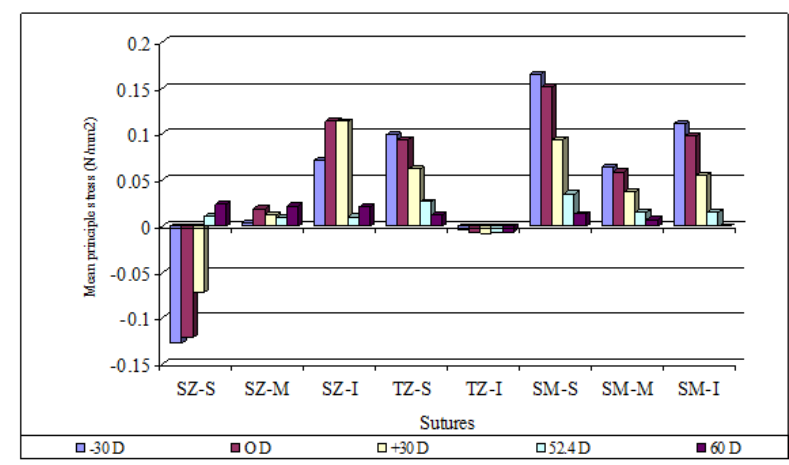

Graph 2. Mean Principal Stresses in the Anatomic Areas Resisting Backward Displacement of the Complex

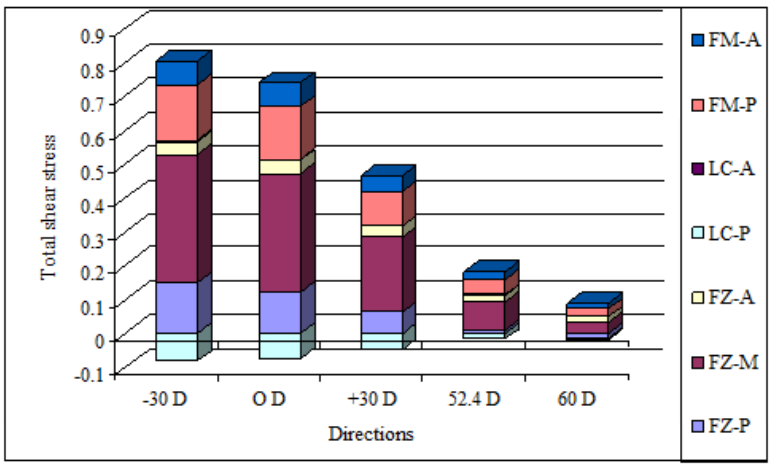

Graph 3. Total Shear Stresses in the Anatomic Areas Resisting Upward Displacement of the Complex 


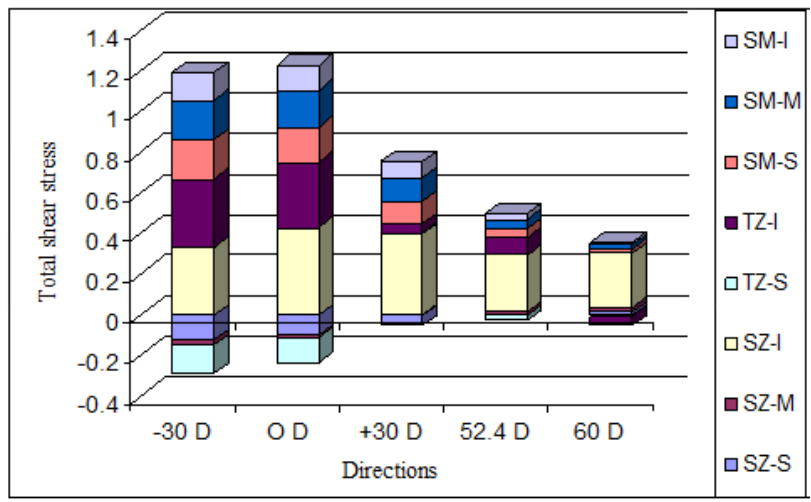

Graph 4. Total Shear Stresses in the Anatomic Areas Resisting Backward Displacement of the Complex

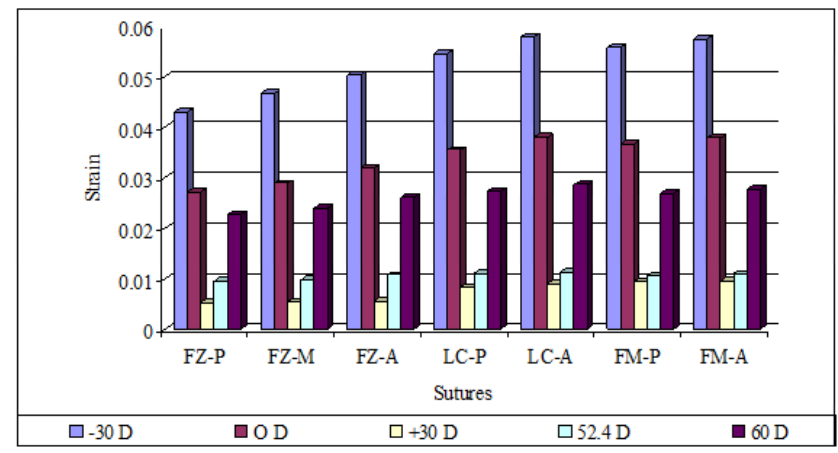

Graph 5. Strain in the Anatomic areas Resisting Upward Displacement of the Complex

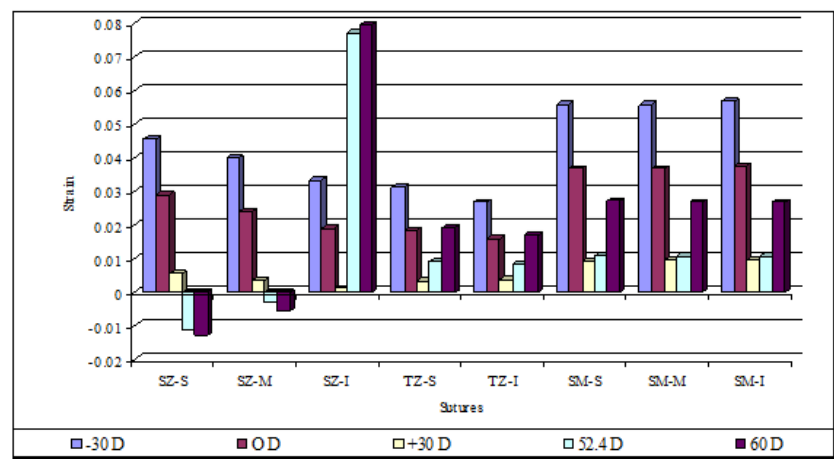

Graph 6. Strain in the Anatomic Areas Resisting Backward Displacement of the Complex

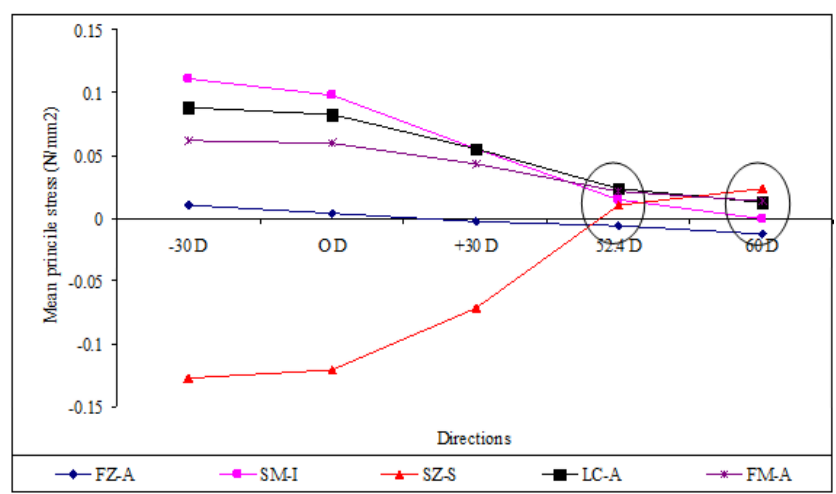

Graph 7. Association between Changes in Mean Principal Stresses at Five Different Points and Force Directions to the Functional Occlusal Plane Determined by the Maxillary Dentition

\section{DISCUSSION}

FEM is a powerful contemporary research tool that has been used to study the stress distribution of non-living as well as natural and restored craniofacial structures affected by threedimensional stress fields, which are difficult to assess otherwise.

The three-dimensional FEM used in the present study provides the freedom to simulate orthodontic force systems applied clinically and allows analysis of the response of the craniofacial skeleton to the orthodontic loads in threedimensional space.

The directions of loading chosen in the present study were taken so as to simulate clinical conditions. $30^{\circ}$ inferior to the occlusal plane represents cervical traction; $0^{0}$ represents a straight pull headgear; $30^{\circ}$ superior to the occlusal plane represents an occipital pull headgear and $60^{\circ}$ superior to the occlusal plane represents the high pull or parietal pull headgear. The orthopaedic loading of $52.4^{0}$ to the occlusal plane was based on previous studies.

The posterior and anterior parts of the frontozygomatic suture showed almost uniform tensile stresses, which turned to compressive, when the direction of loading changed to $52.4^{0}$ and $60^{\circ}$. However, the middle part of the suture showed tensile stresses which were much higher than observed in the anterior and posterior regions.

The lamina cribrosa showed almost uniformly compressive forces which decreased in magnitude as the force direction became more vertical. Throughout the loading range, the posterior part of the suture showed much higher stresses than the anterior.

The posterior part of the frontomaxillary suture showed tensile stresses, which decreased as the direction of pull became more upwards and showed slight compressive stress when the direction of pull changed to $60^{\circ}$. The anterior part of the suture showed compressive stresses, which again decreased in magnitude as the direction of pull became more vertical.

The superior part of the sphenozygomatic suture showed tensile stresses, which became compressive at $52.4^{\circ}$ and $60^{\circ}$. However, the middle and inferior parts of the suture were uniformly compressive, irrespective of the force direction, showing the least stresses at the direction of 52.40.

In the inferior regions of the temporozygomatic suture, slight tensile stresses were induced in loading with forces applied in different directions, whereas stresses in the superior region were mainly compressive.

Stresses in the superior, middle and inferior regions of the sphenomaxillary suture were mainly compressive in nature, with a substantial decrease in magnitude, in loading with more superiorly directed forces.

The total amount of shear stress at seven anatomic points resisting upward displacement of the nasomaxillary complex for each of five directions was calculated. When a downward force of $30^{\circ}$ degrees was applied, total shear stress was highest, indicating a substantial shear deformation of the sutural structure. These stresses decreased gradually when the direction was varied from $30^{\circ}$ inferior to $52.4^{\circ}$ or $60^{\circ}$ superior. This indicates that the loading directions of $52.4^{0}$ and $60^{\circ}$ produce least shear deformation in the anatomic areas resisting superior displacement of the complex. 
The total amount of shear stresses at eight anatomic points in the three sutures resisting backward displacement of the nasomaxillary complex for each of five directions was calculated. In loading with a posteriorly directed horizontal force, total shear stress was greatest, indicating the sliding of two adjacent bones and the subsequent substantial shear deformation of the sutural structure associated with counter clockwise rotation of the complex.

Strain or displacement for all the six sutures was calculated for all the five loading conditions. Maximum strain was seen when load was applied at $30^{\circ}$ inferior to the occlusal plane. Minimum strain was seen at $30^{\circ}$ superior to the occlusal plane.

At headgear loading directions of $52.4^{\circ}$ and $60^{\circ}$, the sphenozygomatic suture showed negative strain in its superior and middle regions and high positive strain in its inferior regions. This indicates a bending of the sphenozygomatic suture, with the inferior regions showing a widening of the suture, compared to compression in the superior and middle regions of the suture.

The stresses exhibited a gradual increase or decrease approaching a uniform level of compressive stress as the direction was varied from $-30^{0}$ to $60^{\circ}$ to the functional occlusal plane. Thus, variation in these stresses decreased and the nature of stresses became more uniform when directing the line of force closer to the CRe of the nasomaxillary complex.

\section{CONCLUSION}

Stress distribution in the nasomaxillary complex was investigated by means of 3-Dimensional Finite Element Analysis. A finite element model of the craniofacial complex was created, that consisted of 56052 nodes and 236685 elements. An extraoral force of $1.0 \mathrm{Kgf}$ was applied to the maxillary first molar in a posterior direction, $30^{\circ}$ inferior, parallel and $30^{\circ}, 52.4^{\circ}$ and $60^{\circ}$ superior to the occlusal plane. Mean Principal stresses, Shear stresses and Strain were evaluated at six anatomic areas resisting posterior and superior displacement of the complex. The following results were obtained:

1. When $30^{\circ}$ inferior, parallel and $30^{\circ}$ superior forces were applied, considerable variation in normal stresses at the sutural interfaces was observed in association with substantial shear stresses.

2. In loading with forces in $52.4^{\circ}$ and $60^{\circ}$ superior directions, compressive stresses were similarly generated in most anatomic areas and both the normal and shear stresses reduced and exhibited a convergence to a certain level.

3. As the force direction approached that of the CRe, mean principal stresses approached a uniform level of compressive stress.

4. Maximum strain or displacement of all the sutures was observed at a force direction of $-30^{\circ}$. Strain approached to a minimum level at a force direction of $30^{\circ}$ and $52.4^{0}$.

These findings show that the stress distribution in the sutures varies in relation to the direction of force. Force applied in the direction closest to that of the CRe may produce the most effective sutural modification for controlling maxillary growth.

\section{REFERENCES}

[1] Barton JJ. High pull headgear versus cervical traction: a cephalometric comparison. Am J Orthod 1972;62(5):517-29.

[2] Kloehn SJ. Guiding alveolar growth and eruption of teeth to reduce treatment time and produce a more balanced denture and face. The Angle Orthodontist 1947;17(1):10-33.

[3] Proffit WR. Contemporary orthodontics. Mosby: St. Louis, 2001:494-508.

[4] Nanda R, Hickory W. Zygomaticomaxillary suture adaptations incident to anteriorly-directed forces in rhesus monkeys. Angle Orthod 1984;54(3):199-210.

[5] Wieslander L. The effect of force on craniofacial development. Am J Orthod 1974;65(5):531-8.

[6] Droschl H. The effect of heavy orthopedic forces on the maxilla in the growing Saimiri sciureus (squirrel monkey). Am J Orthod 1973;63(5):449-61.

[7] Elder JR, Rodger HT. Cephalometric and histologic changes produced by extraoral high-pull traction to the maxilla in Macaca mulatta. Am J Orthod 1974;66:599-617.

[8] Meldrum RJ. Alterations in the upper facial growth of Macaca mulatta resulting from high-pull headgear. Am J Orthod 1975;67(4):393-411.

[9] Triftshauser R, Walters RD. Cervical retraction of the maxillae in the Macaca mulatta monkey using heavy orthopedic force. Angle Orthod 1976;46(1):37-46.

[10] Katsaros C, Zissis A, Bresin A, et al. Functional influence of sutural bone apposition in the growing rat. Am J Orthod Dentofac Orthop 2006;129(3):352-7.

[11] Kragt G, Duterloo HS, Bosch JJ. The initial reaction of a macerated human skull caused by orthodontic cervical traction determined by laser metrology. Am J Orthod 1982;81(1):49-56.

[12] Poulton DR. The influence of extraoral traction. Am J Orthod 1967;53(1):8-18.

[13] Armstrong MM. Controlling the magnitude, direction and duration of extraoral force. Am J Orthod 1971;59(3):217-43.

[14] Watson WG. A computerize appraisal of the high-pull face-bow. Am J Orthod 1972;62(6):561-79.

[15] Baumrind S, Korn EL, Molthen R, et al. Changes in facial dimensions associated with the use of forces to retract the maxilla. Am J Orthod 1981;80(1):17-30.

[16] Baumrind S, Korn EL. Patterns of change in mandibular and facial shape associated with the use of forces to retract the maxilla. Am J Orthod 1981;80(1):31-47.

[17] Pfeiffer JP, Grobety D. A philosophy of combined orthopedic-orthodontic treatment. Am J Orthod 1982;81(3):185-201.

[18] Baumrind S, Korn EL, Isaacson RJ, et al. Quantitative analysis of the orthodontic and orthopedic effects of maxillary traction. Am J Orthod 1983;84(5):384-98.

[19] Boecler PR, Riolo ML, Keeling SD, et al. Skeletal changes associated with extraoral appliance therapy: an evaluation of 200 consecutively treated cases. Angle Orthod 1989;59(4):263-70. 
[20] Lagerstrom LO, Nielsen IL, Lee R, et al. Dental and skeletal contributions to occlusal correction in patients treated with the high-pull headgear-activator combination. Am J Orthod Dentofac Orthop 1990;97(6):495-504.

[21] Ucem TT, Yuksel S. Effects of different vectors of force applied by combined headgear. Am J Orthod Dentofacial Orthop 1998;113(3):316-23.

[22] Lima Filho RM, Lima AL, de Oliveira Ruellas AC. Longitudinal study of anteroposterior and vertical maxillary changes in skeletal class II patients treated with Kloehn cervical headgear. Angle Orthod 2003;73(2):187-93.

[23] Kragt G, Duterloo HS. The initial effects of orthopedic forces: a study of alterations in the craniofacial complex of a macerated human skull owing to highpull headgear traction. Am J Orthod 1982;81(1):57-64.

[24] Kragt G, Duterloo HS, Algra AM. Initial displacement and variation of eight human skulls owing to high pull traction determined with laser holography. Am J Orthod 1986;89(5):399-406.

[25] Zentner A, Sergl HG, Filippidis G. A holographic study of variations in bone deformations resulting from different headgear forces in a macerated human skull. Angle Orthod 1996;66(6):463-72.

[26] Billiet T, de Pauw G, Dermaut L. Location of the centre of resistance of the upper dentition and the nasomaxillary complex. An experimental study. Eur J Orthod 2001;23(3):263-73.
[27] Dermaut LR, Kleutghen JP, De Clerck HJ. Experimental determination of the center of resistance of the upper first molar in a macerated, dry human skull submitted to horizontal headgear traction. Am J Orthod Dentofacial Orthop 1986;90(1):29-36.

[28] Verrue V, Dermaut L, Verhegghe B. Three-dimensional finite element modelling of a dog skull for the simulation of initial orthopaedic displacements. Eur J Orthod 2001;23(5):517-27.

[29] Jafari A, Shetty KS, Kumar M. Study of stress distribution and displacement of various craniofacial structures following application of transverse orthopedic forces-a three-dimensional FEM study. Angle Orthod 2003;73(1):12-20.

[30] Cattaneo PM, Dalstra M, Melsen B. The finite element method: a tool to study orthodontic tooth movement. J Dent Res 2005;84(5):428-33.

[31] Tanne K, Matsubara S. Association between the direction of orthopedic headgear force and sutural responses in the nasomaxillary complex. Angle Orthod 1996;66(2):125-30.

[32] Mantysaari R, Kantomaa T, Pirttiniemi P, et al. The effects of early headgear treatment on dental arches and craniofacial morphology: a report of a two year randomizes study. Eur J Orthod 2004;26(1):59-64. 